\title{
Software Engineering Standards and Guides for Very Small Entities: Implementation in two start-ups
}

\author{
Claude Y. Laporte ${ }^{1}$, Rory V. O’Connor ${ }^{2}$ and Luis Hernán García Paucar ${ }^{3}$ \\ ${ }^{1}$ École de technologie supérieure, Montréal, Canada \\ ${ }^{2}$ Schoolof Computing, Dublin City University, Dublin, Ireland \\ ${ }^{3}$ Universidad Peruana de Ciencias Aplicadas, Lima, Peru \\ Claude.Y.Laporte@etsmtl.ca,roconnor@computing.dcu.ie,luis.garcia@upc.edu.pe
}

\begin{abstract}
Keywords: Very Small Entities, ISO Standards, ISO/IEC 29110, certification, VSE.
Abstract: $\quad$ Very small entities, enterprises, organizations, projects or departments with up to 25 people, are very important to the worldwide economy. However it has ben established that such entities often do not utilize existing standards and frameworks. To address the needs of Very Small Entities (VSEs), a set of international standards and guides known as ISO/IEC 29110 has been developed. In this paper we present the results of early trials of this standard in two IT start-ups VSEs. A Peruvian VSE was recently audited and issued an ISO/IEC 29110 certificate of conformity.
\end{abstract}

\section{INTRODUCTION}

For many small and very small software companies, implementing controls and structures to properly manage their software development activity is a major challenge. Administering software development in this way is usually achieved through the introduction of a software process. All software companies are not the same and vary according to factors including size, market sector, time in business, management style, product range and geographical location. For example, a software company operating in India may have a completely different set of operational problems when compared to a software company in Canada, Mexico or Ireland. Even within a single geographical area such as Ireland, the range of operational issues faced by a small local Irish-owned firm can be radically different to those affecting a multinational subsidiary. The fact that all companies are not the same raises important questions for those who develop software process and process improvement models. To be widely adopted by the software industry, any process or process improvement model should be capable of handling the differences in the operational contexts of the companies making up that industry. But process improvement models, though highly publicized and marketed, are far from being extensively deployed and their influence in the software industry therefore remains more at a theoretical than practical level.

Software development small and very small have the challenge of handling multiple small-scale, fastmoving projects allowing little room for unwieldy management processes, but still requiring an efficient and straightforward monitoring process (Coleman et al, 2008) Moreover due to the small number of people involved in the project and the organization, most of the management processes are performed through an informal way and less documented (O'Connor and Laporte, 2012). The perception of heavyweight processes, especially in terms of documentation, cost and nonalignment with current development process, are among the reasons why the companies did not plan to adopt a lifecycle standard in the short to medium term (Basri et al, 2010) (Mora et al, 2011).

The definition of "Small" and "Very Small" Entities is challengingly ambiguous, as there is no commonly accepted definition of the terms. The term "very small entity" (VSE) had been defined by the ISO/IEC JTC1/SC7 Working Group 24 and subsequently adopted for use in the new ISO/IEC 29110 process lifecycle standard as being "an entity (enterprise, organization, department or project) having up to 25 people" (Laporte et al, 2008). 
Industry recognizes the value of Very Small Entities (VSEs) in contributing valuable products and services. A large majority of enterprises worldwide are VSEs. A large majority of enterprises worldwide are VSEs. In Europe, for instance, as illustrated in Table 1, over 92\% of enterprises are micro-enterprises. They have fewer than nine employees. Micro enterprises account for $70 \%$ to $90 \%$ of enterprises in OECD countries and about $57 \%$ in USA. In Canada, close to 98 percent of businesses are small businesses with fewer than 50 employees. About 32 percent of these have between one and 19 employees (Statistics Canada 2008).

Table 1: Size of enterprises in Europe (Moll 2013)

\begin{tabular}{|l|c|c|c|}
\hline \multicolumn{1}{|c|}{ Type } & $\begin{array}{c}\text { Number of } \\
\text { Employees }\end{array}$ & $\begin{array}{c}\text { Annual } \\
\text { turnover }\end{array}$ & $\begin{array}{c}\text { No. of } \\
\text { enterprises } \\
\text { (\% of overall) }\end{array}$ \\
\hline Micro & $1-9$ & $\leq 2 \mathrm{M}$ & 92.2 \\
\hline Small & $10-49$ & $\leq 10 \mathrm{M}$ & 6.5 \\
\hline Medium & $50-249$ & $\leq 50 \mathrm{M}$ & 1.1 \\
\hline Total & 87100000 & & 98.8 \\
\hline Large & $>250$ & $>50 \mathrm{M}$ & \\
\hline Total & 42990000 & & 0.2 \\
\hline
\end{tabular}

VSEs have unique characteristics, which make their business styles different to larger organizations and therefore most of the management processes are performed through a more informal and less documented manner (O'Connor et al, 2010). Furthermore there is an acknowledged lack of adoption of standards in small and very small companies, as the perception is that they have been developed for large software companies and not with the small organisation in mind (O'Connor and Coleman, 2009). As smaller software companies have fewer resources in term of people and money there are many challenges (Basri et al, 2011).

There is evidence that the majority of small and very small software organizations are not adopting existing standards / proven best practice models because they perceive the standards as being developed by large organizations and orientated towards large organizations, thus provoking the debate the in terms of number of employees, size does actually matter (O'Connor and Coleman, 2006). Studies have shown that small firms' negative perceptions of process model standards are primarily driven by negative views of cost, documentation and bureaucracy (Petkov et al, 2008). In addition, it has been reported that SMEs find it difficult to relate standards to their business needs and to justify the application of the international standards in their operations (O'Connor and Basri, 2012). Most SMEs cannot afford the resources for, or see a net benefit in, establishing software processes as defined by current standards and maturity models (Coleman and O'Connor, 2007).

Accordingly a new standard ISO/IEC 29110 "Lifecycle profiles for Very Small Entities" is aimed at meeting the specific needs of VSEs (O'Connor and Laporte, 2011a). The overall objective of this new standard is to assist and encourage very small software organizations in assessing and improving their software process and it is predicted that this new standard could encourage and assist small software companies in assessing their software development process. The approach (O'Connor and Laporte, 2011b) used to develop ISO/IEC 29110 started with the pre-existing international standards, such as the software life cycle standard ISO/IEC/IEEE 12207 and the documentation standard ISO/IEC/IEEE 15289.

There is a wide spectrum of development approaches for organizations developing software. Figure 1 illustrates the spectrum of approaches on 2 axes. The horizontal axis (from left to right) illustrates the level of ceremony, from a low ceremony approach with little documentation (e.g. agile approach) to a high ceremony approach with a comprehensive documentation (e.g. plan driven $\mathrm{CMMI}^{\mathbb{R}}$ approach). The vertical axes illustrate the approaches based on the level of risk. The top axis illustrates a low risk linear approach using a waterfall approach while the lower part of the axis illustrates a risk-driven project using an iterative approach. As we will explain below, ISO/IEC 29110 is located at about the centre of both axes. 


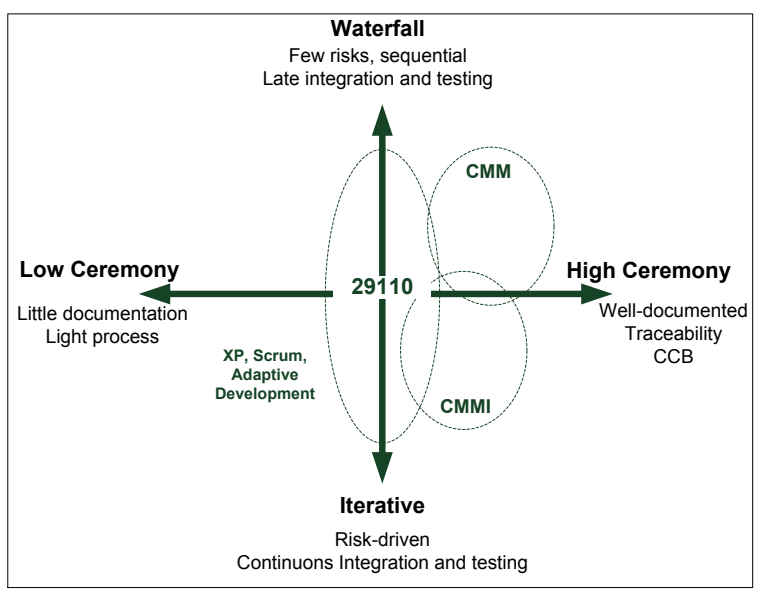

Figure 1: Positioning of the ISO/IEC 29110 (adapted from Kroll 2003)

The working group behind the development of this standard is advocating the use of pilot projects as a mean to accelerate the adoption and utilization of ISO/IEC 29110 by VSEs (O'Connor and Laporte, 2010). Pilot projects are an important mean of reducing risks and learning more about the organizational and technical issues associated with the deployment of new software engineering practices (Laporte et al, 2013a). To date a series of pilot projects for the software engineering profile standard have been completed in several countries with the results published in a variety of literature (Laporte et al, 2013b; O'Connor, 2012; Ribaud et al, 2010).

For most enterprises, but in particular for VSEs, international certifications can enhance credibility, competitiveness and access to national and international markets. Brazil has developed an ISO/IEC 29110 certification process. An ISO/IEC 29110 auditor should be competent in auditing techniques, have expertise in ISO/IEC 29110 and have experience in software development.

\section{INTERNATIONAL STANDARDS FOR VSES}

\subsection{Development}

Since an international standard dedicated to the software life cycle processes was already available, i.e. ISO/IEC/IEEE 12207 (2008), WG24, the ISO/IEC JTC1 SC7 working group mandated to develop the new set of standards for VSEs, used the concept of ISO standardized profiles (SP) to develop the new standards for VSEs developing software. From a practical point of view, a profile is a kind of matrix, which identifies precisely the elements that are taken from existing standards from those that are not. The overall approach followed by WG24 to develop this new standard for VSE consisted of the following steps:

- develop a set of profiles for VSEs not involved in critical software development,

- select the ISO/IEC/IEEE 12207 process subsets applicable to VSEs having up to 25 people,

- select the description of the products, to be produced by a project, using ISO/IEC/IEEE 15289 (2011) standard

- develop guidelines, checklists, templates, examples to support the subsets selected.

\subsection{Generic Profile Group}

The basic requirements of a software development process are that it should fit the needs of the project and aid project success (Clarke 2011). And this need should be informed by the situational context where in the project must operate and therefore, the most suitable software development process is contingent on the context (Clarke et al 2012) (Jeners et al 2013). The core situational characteristic of the entities targeted by ISO/IEC 29110 is size 
Profile Groups are a collection of profiles. The Generic Profile Group has been defined as applicable to VSEs that do not develop critical software. This Profile Group is a collection of four profiles (Entry, Basic, Intermediate, Advanced) providing a roadmap to satisfying a vast majority of VSEs worldwide. VSEs targeted by the Entry Profile are VSEs working on small projects (e.g. at most six person-months effort) and for start-up VSEs. The Basic Profile describes software development practices of a single application by a single project team of a VSE. The Intermediate Profile is targeted at VSEs developing multiple projects with more than one project team. The Advanced Profile is target to VSEs which want to sustain and grow as a competitive software development business.

The ISO/IEC 29110 standards and technical reports targeted by audience. The set of documents for the Basic profile (including ISO/IEC TR 29110-5-1-2:2011 (2011) and ISO/IEC TR 29110-1:2011 (2011) were published in 2011. At the request of WG24, all ISO/IEC 29110 TRs are available at no cost from ISO. The Management and Engineering Guide, the most valuable document for VSEs, has being translated in French and in Spanish by Peru and adopted as a Peruvian national standard. The set of 5 documents has been translated in Portuguese by Brazil and adopted as a Brazilian national standard. The set of 5 documents has been translated in Spanish by Uruguay and adopted as a national standard. Japan has translated and adopted ISO/IEC 29110 as a Japanese national standard. The Management and Engineering guide of the Entry profile has been published in English, in French, Portuguese and in Spanish.

\subsection{Overview of the Basic Profile for VSEs developing software}

At the core of this standard is a Management and Engineering Guide, officially know as ISO/IEC TR 29110-5-1-2, which focuses on Project Management and Software Implementation as illustrated in Figure 1. The purpose of the Basic Profile is to define Software Implementation (SI) and Project Management (PM) processes from a subset of ISO/IEC/IEEE 12207 and ISO/IEC/IEEE 15289 appropriate for VSEs, as illustrated in Figure 2.

The purpose of the Basic Profile is to define Software Implementation (SI) and Project Management (PM) processes from a subset of ISO/IEC/IEEE 12207 and ISO/IEC/IEEE 15289 appropriate for VSEs. The main reason to include project management is that the core business of VSEs is software development and their financial success depends on successful project completion within schedule and on budget, as well as on making a profit. The high-level view and the relationships between the Software Implementation Process and the Project Management processes are illustrated in Figure 2.

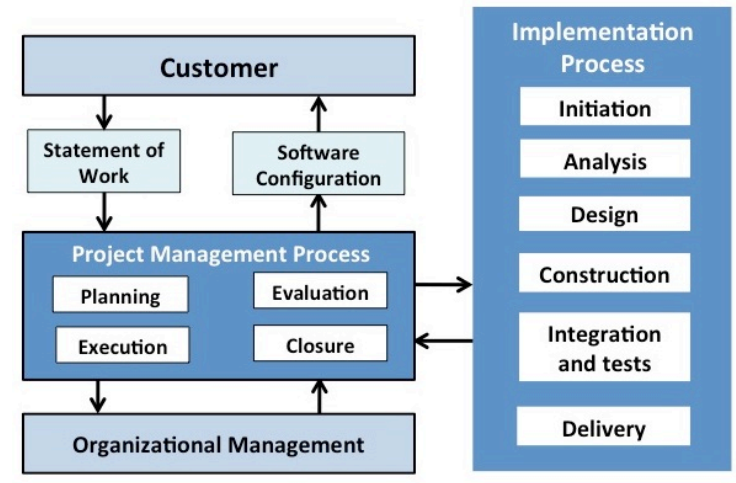

Figure 2: Basic profile processes and activities (Laporte et al, 2014c)

\subsection{Structure of the Basic Profile}

This standard defines two processes, Software Implementation and Project Management. The purpose of the Software Implementation process is the systematic performance of the analysis, design, construction, integration and tests activities for new or modified software products according to the specified requirements. 
The purpose of the Project Management process is to establish and carry out in a systematic way the tasks of the software implementation project, which allows complying with the project's objectives in the expected quality, time and cost.

The seven objectives of the PM process are:

- The Project Plan for the execution of the project is developed according to the Statement of Work and reviewed and accepted by the Customer. The tasks and resources necessary to complete the work are sized and estimated.

- Progress of the project is monitored against the Project Plan and recorded in the Progress Status Record.

- The Change Requests are addressed through their reception and analysis. Changes to software requirements are evaluated for cost, schedule and technical impact.

- Review meetings with the Work Team and the Customer are held. Agreements are registered and tracked.

- Risks are identified as they develop and during the conduct of the project.

- A software Version Control Strategy is developed. Items of Software Configuration are identified, defined and baselined. Modifications and releases of the items are controlled and made available to the Customer and Work Team including the storage, handling and delivery of the items.

- Software Quality Assurance is performed to provide assurance that work products and processes comply with the Project Plan and Requirements Specification.

The four activities of the Project Management Process are:

- Project Planning: The primary objective of this process is to produce and communicate effective and workable project plans. This process determines the scope of the project management and technical activities, identifies process outputs, project tasks and deliverables, establishes schedules for project task conduct, including achievement criteria, and required re- sources to accomplish project tasks.

- Project Plan Execution: To implement the actual work tasks of the project in accordance with the project plan. Ideally when the project plan has been agreed and communicated to all teams members, work of the development of the product, which is the subject of the project, should commence.

- Project Assessment and Control: Purpose is to determine the status of the project and ensure that the project performs according to plans and schedules, within projected budgets and it satisfies technical objectives.

- Project Closure: Typically involves releasing the final deliverables to the customer, handing over project documentation to the business, terminating supplier contracts, releasing project resources and communicating project closure to all stakeholders.

The purpose of the Software Implementation process is to achieve systematic performance of the analysis, design, construction, integration, and test activities for new or modified software products according to the specified requirements. The seven objectives of the SI process are

- Tasks of the activities are performed through the accomplishment of the current Project Plan.

- Software requirements are defined, analyzed for correctness and testability, approved by the Customer, baselined and communicated.

- Software architectural and detailed design is developed and baselined. It describes the Software Components and internal and external interfaces of them.

- Software Components defined by the design are produced. Unit test are defined and performed to verify the consistency with requirements and the design.

- Software is produced performing integration of Software Components and verified using Test Cases and Test Procedures. Results are recorded at the Test Report.

- A Software Configuration, that meets the Requirements Specification as agreed to with the Customer, which includes user, operation and maintenance documentations, is integrated, baselined and stored at the Project Repository.

- Verification and Validation Tasks of all required work products are performed using the defined criteria to achieve consistency among output and input products in each activity. 
The activities of the Software Implementation Process are:

- Software Implementation Initiation: Ensures that the Project Plan established in Project Planning activity is committed to by the Work Team.

- Software Requirements Analysis: Analyzes the agreed Customer's requirements and establishes the validated project requirements. The activity provides:

- Software Architectural and Detailed Design: Transforms the software requirements to the system software architecture and software de- tailed design.

- Software Construction: Develops the soft- ware code and data from the Software Design.

- Software Integration and Tests: Ensures that the integrated Software Components satisfy the software requirements.

- Product Delivery: Provides the integrated software product to the Customer.

As illustrated in figure 2, the customer's statement of work (SOW) is used to initiate the PM process. The project plan will be used to guide the execution of the software requirements analysis, software architectural and detailed design, software construction, and software integration and test, and product delivery activities. The PM process closure activity will deliver the Software Configuration (i.e. a set of software products such as documentation, code and tests) and will obtain the customer's acceptance to formalize the end of the project.

\subsection{Development of Deployment Packages}

In order to facilitate the implementation, by VSEs, of a Profile, a set of Deployment Packages (2013) are available. A deployment package is a set of artefacts developed to facilitate the implementation of a set of practices, of the selected framework, in a VSE. But, a deployment package is not a complete process reference model. Deployment packages are not intended to preclude or discourage the use of additional guidelines that VSEs find useful.

The elements of a typical deployment package are: technical description, relationships with ISO/IEC 29110, key definitions, detailed description of processes, activities, tasks, roles and products, template, checklist, example, references and mapping to standards and models, and a list of tools. The mapping is only given as information to show that a Deployment Package has explicit links to Part 5, ISO standards, such as ISO/IEC/IEEE 12207, or models such as the CMMI developed by the Software Engineering Institute. Hence by deploying and implementing a package (O'Connor and Sanders, 2013) a VSE can see its concrete step to achieve or demonstrate coverage to Part 5.

A novel approach was taken to assist VSEs with the deployment of ISO/IEC 29110 and to provide guidance on the actual implementation this standard. A set of Deployment Packages (DPs) have been developed to define guidelines and explain in more detail the processes defined in the ISO/IEC 29110 profiles (O'Connor and Laporte, 2014). The elements of a typical DP are: description of processes, activities, tasks, steps, roles, products, templates, checklists, examples, references and mapping to standards and models, and a list of tools.

DPs were designed such that a VSE can implement its content, without having to implement the complete ISO/IEC 29110 framework, i.e. all the management and engineering activities, at the same time. A set of nine DPs have been developed and are freely available from (DP 2014). Figure 3 illustrates the set of DPs developed to support the Basic Profile. 


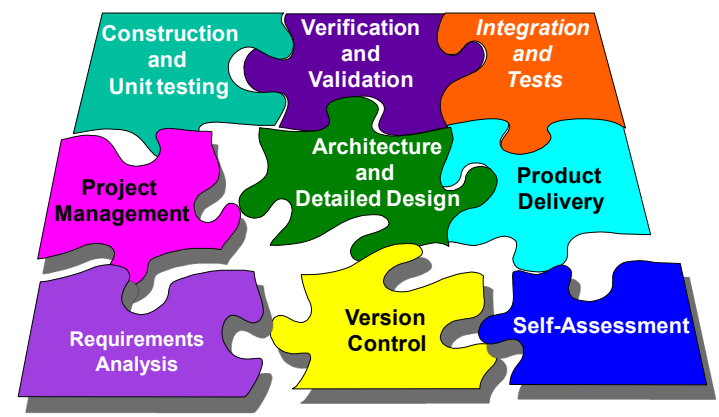

Figure 3: DPs support for Basic Profile (Laporte and O'Connor, 2014b)

\section{IMPLEMENTATION TRIALS}

The working group (ISO/IEC JTC1/SC7 WG 24) behind the development of this standard is advocating the use of pilot projects as a mean to accelerate the adoption and utilization of ISO/IEC 29110. Pilot projects are an important means of reducing risks and learning more about the organizational and technical issues associated with the deployment of new software engineering practices.

In this section we will present 2 trial implementations of ISO/IEC 29110 in IT start-ups. The purpose of these trials is to illustrate the usage of this standard in an industrial context and to provide feedback to standards authors. Whilst not a detailed methodological approach to validation of this standard and whilst acknowledging the validation limitations, we believe that these high level results are useful to researchers and practitioners alike.

\subsection{Implementation in a Peruvian IT start-up}

Over $98 \%$ of Perú are micro, small and medium enterprises (MSMEs) having fewer than 10 workers. About 7,6 million people work in companies having fewer than 10 workers. About 14,000 Peruvian companies are associated with the Information Technology and Communications (ITC) industry (Krasner, 1998).

An implementation of ISO/IEC 29110 has been conducted in a four-people start-up VSE created in 2012 (Garcia et al, 2015). During its two years of existence, the VSE has been involved in over 80 projects, most of which have lasted less than two months. The VSE used agile practices to implement software solutions such as Web 2.0 responsive design systems and mobile applications. After completing the implementation of the Basic profile of ISO/IEC 29110, the VSE executed in 2014 a project under contract. The product developed was a software solution that facilitates communication between clients and legal consultants at one of the largest insurance companies in Peru. The solution had to be implemented on a web platform and deployed into a cloud environment.

Since the VSE was using agile methods to implement its software projects, customer requirements were expressed as user stories. For this project, the VSE had determined that the duration of a sprint would be one week. The project had 6 sprints. All software components, test cases, test procedures and user stories were linked through a traceability matrix. A subset of the traceability matrix for a user story is shown in Figure 4. 


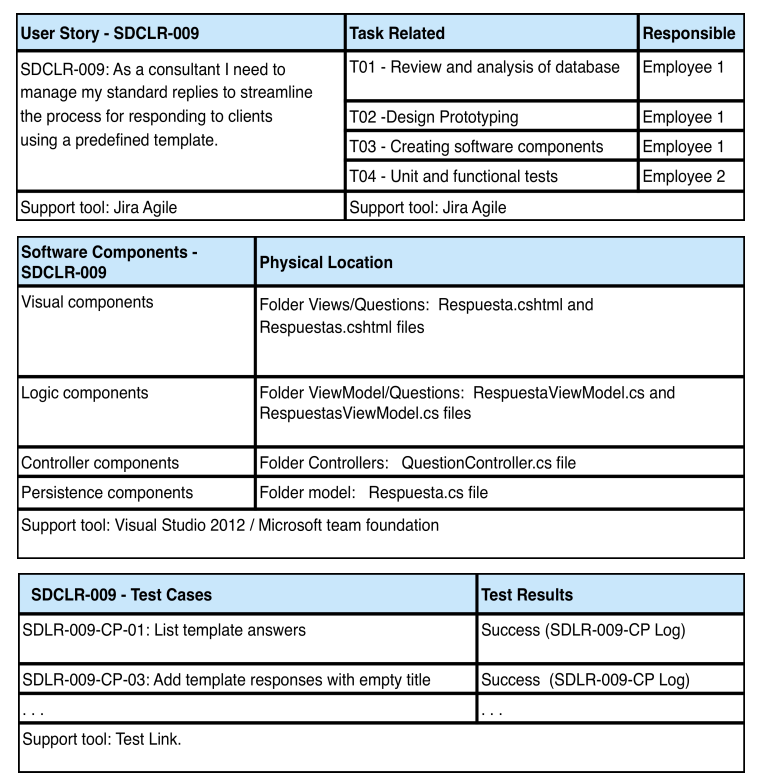

Figure 4: Subset of traceability matrix for one user story (Garcia et al 2015)

As illustrated in Table 2, the total effort to implement the project was 882 hours. The effort devoted to prevention activities such as installation of the environment (servers, tools, etc.) was 14 hours, task execution took 585 hours, reviews took 124 hours and effort to correct defects identified in reviews and in testing took 159 hours. The start-up wasted only $18 \%$ of the total project effort (i.e. 159 hours/882 hours) on rework.

Since it was the first time the VSE had executed the new ISO/IEC 29110 processes in a real project, so there was a learning curve that resulted in additional hours spent on rework for different project tasks. Despite this situation, the result was close to the percentage of rework (i.e. about $15 \%$ to $25 \%$ ) of an organization that has implemented the Capability Maturity Model and is at maturity level 3.

Table 2: effort to execute, detect and correct errors (Garcia et al 2015)

\begin{tabular}{|l|l|l|l|l|}
\hline Title of task & $\begin{array}{l}\text { Prevention } \\
\text { (hours) }\end{array}$ & $\begin{array}{l}\text { Execution } \\
\text { (Hours) }\end{array}$ & $\begin{array}{l}\text { Review } \\
\text { (Hours) }\end{array}$ & $\begin{array}{l}\text { Rework } \\
\text { (Hours) }\end{array}$ \\
\hline Environment installation & 14 & & & \\
\hline Project plan development & & 15 & 3 & 7 \\
\hline $\begin{array}{l}\text { Project plan execution and project assessment } \\
\text { \& control }\end{array}$ & & 108 & & \\
\hline Specification development & & 107 & 28 & 58 \\
\hline Architecture development & & 35 & 10 & 14 \\
\hline Test plan development & & 45 & 8 & 11 \\
\hline Code development and testing & & 253 & 70 & 62 \\
\hline Develop user guide \& maintenance document & & 14 & 5 & 7 \\
\hline Product deployment & & 6 & & \\
\hline Project closure & & 2 & $\mathbf{5 8 5}$ & \\
\hline Total hours & $\mathbf{1 4}$ & $\mathbf{1 2 4}$ & $\mathbf{1 5 9}$ \\
\hline
\end{tabular}

As illustrated in Figure 5, the ISO/IEC 29110 certification process is composed of four stages. In the first stage, a VSE applies for an ISO/IEC 29110 audit and if it is successful, a commercial and technical agreement is entered into with the accreditation body. Then, the initial certification audit begins. If the audit is successful, a three-year initial certificate is issued by a national accreditation body. In this case, the certificate was issued by the Brazilian national accreditation body. 
For the first stage of the audit process, the Peruvian VSE invested about 22 hours. For the initial certification stage, the VSE invested about 63 hours. The cost of the auditor, excluding the travel expenses, was $1,500 \$$. The total effort and cost of an ISO/IEC 29110 audit is very small compared to a typical CMMI official assessment. This start-up became the first Peruvian VSE to obtain an ISO/IEC 29110 certification.

The third stage of a certification cycle involves the completion of two surveillance audits one and two years after obtaining the initial certification. Finally, the fourth stage is the recertification of the VSE; once the 3-year certification cycle has elapsed.

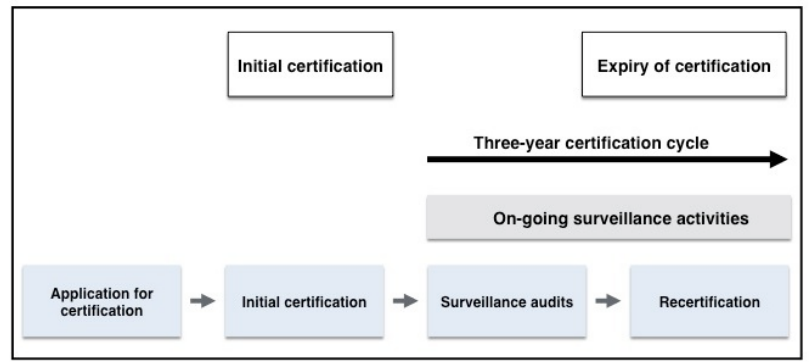

Figure 5: ISO/IEC 29110 certification process (Laporte et al 2014d)

In order to promote the recognition of qualifications between countries, there are international organizations such as the International Accreditation Forum (IAF). The IAF is the world association of conformity assessment accreditation bodies in the fields of management systems, products and services, and to date, it has more than 60 member countries. The Peruvian and the Brazilian accreditation bodies are members of this organization. An ISO/IEC 29110 certificate of conformity issued by an accreditation body member of the IAF is recognized by all members of IAF. The conformity certificate has become a major differentiator with regard to the main competitors of the VSE. The Peruvian start-up VSE has gained access to larger software development projects and increased its customer base. The VSE has increased its number of workers to date, from 4 to 10 employees.

\subsection{Implementation in a Canadian IT start-up}

An implementation project has been conducted in an IT start-up VSE by a team of two (part-time) developers (Laporte et al, 2014c). Their web application allows users to collaborate, share and plan their trips simply and accessible to all. The use of the Basic profile of ISO/IEC 29110 has guided the start-up to develop an application of high quality while using proven practices of ISO 29110. The total effort of this project was nearly 1000 hours. The two members of the team were assigned roles and activities of ISO 29110.

During the software development, a traceability matrix was developed between the software requirements, defined in the requirements specification document, and the software components. Since, in most projects requirements, defined in the requirements activity, are never finalized at the end of this activity, a traceability matrix is very useful. One advantage of such a matrix is the possibility of rapidly identifying the impacted software components when modifications, additions, deletions, of software requirements are done during a project.

Verification tasks, such as peer reviews, were performed on documents such as the requirement specifications and the architecture. The team used the desk-check to review their documents which is inexpensive and easy to implement in any organization and can be used to detect anomalies, omissions, improve a document or present and discuss alternative solutions.

As defined in ISO/IEC 29110, the software integration and tests activity ensures that the integrated Software Components satisfy the software requirements. This activity provides (ISO 2011c):

Work team review of the project plan to determine task assignment.

- Understanding of test cases and procedures and the integration environment. 
- Integrated software components, corrected defects and documented results.

- Traceability of requirements and design to the integrated software product.

- Documented and verified operational and software user documentations.

- Verified software baseline.

To manage the defects detected, a tracking tool was used. Such software allowed the team to do an inventory of problems found during the integration and testing activity, to track problems and to classify them, and to determine a priority for each defect found. In this project, the open source Bugzilla software tool had been used to manage the defects.

The test report presents the results of tests carried out using the test plan. These results are used to illustrate the number of problems found and the progress of the resolution of anomalies. The test plan includes 112 cases which have been successfully completed with the exception test cases connected to one type of defect: the validation of the date format when manually entered by a user. Since this defect was classified as "minor", it was decided not to correct their instances during the first cycle of development. Table 3 illustrates the percentage of defects detected during the execution of the tests for each category of defects.

Table 3: Number and types of defects detected through testing and corrected (Laporte et al 2014c)

\begin{tabular}{|l|l|l|l|}
\hline Seriousness & $\begin{array}{c}\text { No. of } \\
\text { defects } \\
\text { detected }\end{array}$ & $\begin{array}{c}\text { No. of } \\
\text { defects } \\
\text { corrected }\end{array}$ & $\begin{array}{c}\text { \% of } \\
\text { defects } \\
\text { corrected }\end{array}$ \\
\hline Blocker & 3 & 3 & $100 \%$ \\
\hline Critical & 22 & 22 & $100 \%$ \\
\hline Major & 11 & 11 & $100 \%$ \\
\hline Normal & 12 & 12 & $100 \%$ \\
\hline Minor & 19 & 6 & $32 \%$ \\
\hline
\end{tabular}

The defects classified by severity using the following defect classification:

- Blocker: prevents function from being used, no work-around, blocking progress on multiple fronts

- Critical: prevents function from being used, no work-around

- Major: prevents function from being used, but a work-around is possible

- Normal: a problem making a function difficult to use but no special work-around is required

- Minor: a problem not affecting the actual function, but the behaviour is not natural

The members of the start-up have recorded the effort, in person-hours, spent on tasks of the project to the nearest 30 minutes. Table 4 shows, for each major task, the effort to execute the task, the effort required to review a document, such as the software specification document, in order to detect errors and, the effort required to correct the errors (i.e. the rework). As an example, for the development of the software architecture document, it took 42.5 hours to develop, an additional 1.5 hour to conduct a review and an additional 3.5 hours to correct the errors.

As illustrated in table 4 for this start-up project, about $8.9 \%$ (i.e. 89 hours/990.5 hours) of the total project effort has been spent in prevention tasks such as the installation of the server, the workstations and the software tools; and only $12.6 \%$ has been spent on rework (i.e. 125 hours $/ 990.5$ hours). This indicates that the use of appropriate standards, in this case for a start-up company, can guide all the phases of the development of a product such that the wasted effort (i.e. rework) is about the same as a more mature organization (i.e. about level 3 of CMM).

In most start-ups, the wasted effort, for a project similar to this one, would have added about 90 hours (i.e. $30 \%$ of 716 or 215 hours -125 hours). This also implies, that for a net effort of about 6 hours per member per day (if we subtract from an 8-hour day interruptions (e.g. phone call), answering emails, discussions in corridors, etc.), the product would have been ready for delivery to a customer about 15 days, of 6 hours, later than with a project with only $12.6 \%$ of waste. 
Table 4: Effort to execute, detect and correct errors by the 2-member team (Laporte et al 2014c)

\begin{tabular}{|c|c|c|c|c|}
\hline Title of task & Prevention (hours) & Execution (Hours) & Review (Hours) & $\begin{array}{l}\text { Rework } \\
\text { (Hours) }\end{array}$ \\
\hline $\begin{array}{l}\text { Environment } \\
\text { installation }\end{array}$ & 89 & & & \\
\hline $\begin{array}{l}\text { Project plan } \\
\text { development }\end{array}$ & & 35 & 3 & 4 \\
\hline $\begin{array}{l}\text { Project plan execution } \\
\text { and project } \\
\text { assessment \& control }\end{array}$ & & 47 & & \\
\hline $\begin{array}{l}\text { Specification \& } \\
\text { prototype } \\
\text { development }\end{array}$ & & 199.5 & 7 & 18 \\
\hline $\begin{array}{l}\text { Architecture } \\
\text { development }\end{array}$ & & 42.5 & 1.5 & 3.5 \\
\hline Test plan development & & 12.5 & 1 & 2 \\
\hline $\begin{array}{l}\text { Code development } \\
\text { and testing }\end{array}$ & & 361 & 47 & 96.5 \\
\hline $\begin{array}{l}\text { Develop user guide \& } \\
\text { maintenance } \\
\text { document }\end{array}$ & & 8 & 1 & 1 \\
\hline Web site deployment & & 8.5 & & \\
\hline Project closure & & 2 & & \\
\hline Total hours & 89 & 716 & 60.5 & 125 \\
\hline
\end{tabular}

These two projects have demonstrated that, by using ISO/IEC 29110, it was possible to properly plan the project and develop the software product using proven software practices documented in standards as well as not interfering with the creativity during the development of their web site. People who think that standards are a burden, an unnecessary overhead and a treat to creativity should look at this start-up project and revisit their results.

\section{CONCLUSIONS AND FUTURE WORK}

The relationship between the success of a software company and the software process it utilized has been investigated (Laporte and O'Connor, 2014a) (O'Connor and Basri, 2014) showing the need for all organizations, not just VSEs to pay attention to software process practices such as ISO standards. As ISO/IEC 29110 is an emerging standard there is much work yet to be completed. The main remaining work item is to finalize the development of the remaining two software profiles of the Generic Profile Group: (a) Intermediate management of more than one project and (b) Advanced - business management and portfolio management practices.

The ISO working group, initially mandated to develop the ISO/IEC 29110 for software, was also mandated to develop a similar approach for VSEs involved in systems engineering (Laporte and O'Connor, 2014b). In August 2014, ISO published the ISO/IEC 29110 systems engineering and management guide of the Basic profile ISO/IEC TR 29110-5-6-2:2014 (2014). The systems engineering and management guide of the Entry profile has been published in 2015 as ISO/IEC TR 29110-5-6-1:2015 (2015).

With any new initiative there is much to be learned from conducting pilot projects. One issue of major importance to VSEs which is emerging from these pilot projects and similar work by the ISO working group is the need for a light-weight flexible approach to process assessment. Whilst work is currently underway on an assessment mechanism for ISO/IEC 29110 (ISO, 2011b), a clear niche market need is emerging which may force the process assessment community to change their views on how process assessments are carried out for VSEs. In particular there is a strong need to ensure that VSEs are not required to invest anything similar in terms of time, money and other resources on process assessments, as may be expected from their larger SMEs 
(small and medium enterprises), or even MNC (multinational corporations) counterparts. Indeed some form of self-assessment, possibly supported by Internet based tools, along with periodic spot-checks may be a suitable alternative to meet the unique needs of VSEs. It is clear that the process assessment community will have to rethink process assessment, new methods and ideas for assessing processes in VSEs.

It is expected that some VSEs will use the technology developed on their own, other VSEs will get some help from government organizations, such as training or coaching, and some large organizations will impose the ISO/IEC 29110 standards on the VSEs that supply components for their products. A few countries have opted for the 'survival of the fittest' strategy for their VSEs, i.e. an approach where a government does not intervene in the marketplace and lets the market decide which VSEs will survive. At the same time, a number of government agencies, universities, research centers and associations are working to determine how to help VSEs.

\section{ADDITIONAL INFORMATION}

The following web site provides more information:

http://profs.logti.etsmtl.ca/claporte/English/VSE/index.html

\section{REFERENCES}

Basri, S., \& O'Connor, R. V. 2010. Evaluation on knowledge management process in very small software companies: a survey, 5th Knowledge Management International Conference, Terengganu, Malaysia, May 2010.

Basri S, O'Connor RV. 2011 A study of software development team dynamics in SPI. Systems, Software and Services Process Improvement (EuroSPI 2011), CCIS, vol. 172, pp. 143-154. Springer-Verlag.

Basri, S., \& O'Connor, R. (2012). A study of knowledge management process practices in very small software companies. American Journal of Economics and Business Administration, 3(4), 636-644

Coleman, G., O'Connor, R. 2006. Software Process in Practice: A Grounded Theory of the Irish Software Industry. In: Richardson, I., Runeson, P., Messnarz, R. (eds.) EuroSPI 2006. LNCS, vol. 4257, pp. 28-39. Springer, Heidelberg.

Coleman, G., \& O'Connor, R. V. (2008). An investigation into software development process formation in software startups. Journal of Enterprise Information Management, 21(6), 633-648.

Clarke, P., \& O'Connor, R. 2010. Harnessing ISO/IEC 12207 to Examine the Extent of SPI Activity in an Organisation. In Systems, Software and Services Process Improvement (pp. 25-36). Springer Berlin Heidelberg.

Clarke, P., O'Connor, R.V. 2011. The Meaning of Success for Software SMEs: An Holistic Scorecard Based Approach. Systems, Software and Services Process Improvement (EuroSPI 2011), CCIS, vol. 172, pp. 272-83. Springer-Verlag, Heidelberg.

Clarke, P. and O'Connor, R., The situational factors that affect the software development process: Towards a comprehensive reference framework, Journal of Information and Software Technology, Vol. 54, Issue 5, May 2012. pp. 433-447

DP 2014. Deployment Packages repository, [online] available from: http://profs.logti.etsmtl.ca/claporte/English/VSE/index.html

Krasner, H. 1998. Using the cost of quality approach for software. Crosstalk - The Journal of Defense Software Engineering 11 (November):6-11

Garcia, L., Laporte, C.Y., Arteaga, J., Bruggmann, M., Implementation and Certification of ISO/IEC 29110 in an IT Startup in Peru, Software Quality Professional Journal, ASQ, vol. 17, no. 2, 2015, pp 16-29.

ISO/IEC/IEEE 12207:2008, Systems and software engineering- Software life cycle processes. International Organization for Standardization/International Electrotechnical Commission: Geneva, Switzerland.

ISO/IEC/IEEE 15289:2011, Systems and software engineering - Content of systems and software life cycle process information products (Documentation), International Organization for Standardization/International Electrotechnical Commission: Geneva, Switzerland

ISO/IEC 29110-4-1:2011, Software Engineering -- Lifecycle Profiles for Very Small Entities (VSEs) - Part 4-1: Profile specifications: Generic profile group. Geneva: International Organization for Standardization (ISO), 2011.

ISO/IEC TR 29110-1:2011, "Software Engineering - Lifecycle Profiles for Very Small Entities (VSEs) - Part 1: Overview". Geneva: International Organization for Standardization (ISO), 2011. Available at no cost from ISO at: http://standards.iso.org/ittf/PubliclyAvailableStandards/c051150 ISO IEC TR 29110-1 2011.zip 
ISO/IEC TR 29110-5-6-2:2014 - Systems Engineering - Lifecycle Profiles for Very Small Entities (VSEs) - Management and engineering guide: Generic profile group: Basic profile, International Organization for Standardization/International Electrotechnical Commission: Geneva, Switzerland. Available at no cost from ISO at: http://standards.iso.org/ittf/PubliclyAvailableStandards/c063371 ISO IEC 29110-5-6 2 2014.zip

ISO/IEC TR 29110-5-6-1:2015 - Systems Engineering - Lifecycle Profiles for Very Small Entities (VSEs) - Management and engineering guide: Generic profile group: Entry profile, International Organization for Standardization/International Electrotechnical Commission: Geneva, Switzerland. Available at no cost from ISO at http://standards.iso.org/ittf/PubliclyAvailableStandards/index.html

Jeners, S., Clarke, P., O’Connor, R. V., Buglione, L., and Lepmets, M. Harmonizing Software Development Processes with Software Development Settings - A Systematic Approach, In McCafery, F., O'Connor, R.V. and Messnarz R. (Eds), Systems, Software and Services Process Improvement, CCIS 364, Springer-Verlag, 2013

Kroll, P., and P. Kruchten. 2003. The Rational unified process made easy: A practitioner's guide to the RUP. Boston: Addison-Wesley Longman Publishing Co.

Laporte, C. Y., O’Connor, R. V. 2014a. A Systems Process Lifecycle Standard for Very Small Entities: Development and Pilot Trials, In Barafort, B., O'Connor, R.V. and Messnarz R. (Eds), Systems, Software and Services Process Improvement, CCIS Vol. 425, Springer-Verlag.

Laporte, C.Y.; O'Connor, Rory V. 2014b. Systems and Software Engineering Standards for Very Small Entities: Implementation and Initial Results. 9th International Conference on the Quality of Information and Communications Technology (QUATIC), pp.38-47, 23-26 Sept.

Laporte, C.Y., Hébert, C., Mineau, C., 2014c. Development of a Social Network Website Using the New ISO/IEC 29110 Standard Developed Specifically for Very Small Entities, Software Quality Professional Journal, ASQ, vol. 16, no. 4, pp 4-25, 2014

Laporte, C.Y., Houde, R., Marvin, J., 2014d. Systems Engineering International Standards and Support Tools for Very Small Enterprises, Paper to be presented at the 24th Annual International Symposium of INCOSE (International Council on Systems Engineering), Las Vegas, US, June 30th-July 3, 2014.

Laporte, C.Y., Séguin, N., Villas Boas, G., 2013b. Seizing the benefits of software and systems engineering standards, ISO Focus+, International Organization for Standardization, February 2013, pp 32-36.

Laporte, C.Y., O'Connor, R., Fanmuy, G., 2013a. International Systems and Software Engineering Standards for Very Small Entities, CrossTalk - The Journal of Defense Software Engineering, May/June 2013, Vol. 26, No 3, pp 28-33.

Laporte, C.Y., Alexandre, S., and O'Connor, R. 2008. A Software Engineering Lifecycle Standard for Very Small Enterprises, R.V. O'Connor et al (Eds) Proceedings of EuroSPI Springer-Verlag, CCIS Vol. 16, pp. 129-141,

Mora, M., O'Connor, R., Raisinghani, M., \& Macías-Luévano, J. 2011. An IT service engineering and management framework (ITS-EMF). International Journal of Service Science, Management, Engineering, and Technology, 2(2), 115 .

Moll, R., 20134. Being prepared - A bird's eye view of SMEs and risk management, ISO Focus+, Geneva, Switzerland: International Organization for Standardization, February 2013.

O'Connor, R. V., \& Coleman, G. 2007. An investigation of barriers to the adoption of software process best practice models. ACIS 2007 Proceedings, 35.

O'Connor R. and Coleman G., 2009. Ignoring 'Best Practice': Why Irish Software SMEs are rejecting CMMI and ISO 9000 , Australasian Journal of Information Systems, Vol. 16, No. 1,

O'Connor, R., Basri, S. and Coleman, G., 2010. Exploring Managerial Commitment towards SPI in Small and Very Small Enterprises, in Riel et al (Eds), Systems, Software and Services Process Improvement, CCIS Vol. 99, Springer-Verlag, pp. 268-278.

O'Connor R. and Laporte, C.Y., 2010. Towards the provision of assistance for very small entities in deploying software lifecycle standards. In Proceedings of the 11th International Conference on Product Focused Software (PROFES '10). ACM.

O'Connor, R. and Laporte, C.Y., 2011a. Deploying Lifecycle profiles for Very Small Entities: An Early Stage Industry View, Proceedings of 11th International SPICE Conference on Process Improvement and Capability dEtermination, CCIS Vol. 155, Springer-Verlag, May 2011.

O'Connor, R. and Laporte, C.Y., 2011b. Using ISO/IEC 29110 to Harness Process Improvement in Very Small Entities, Workshop on SPI in SMEs, 18th European Software Process Improvement Conference, CCIS Vol. 172, SpringerVerlag.

O'Connor, R. 2012. Evaluating Management Sentiment Towards ISO/IEC 29110 in Very Small Software Development Companies. In: Mas, et al. (eds.) Software Process Improvement and Capability Determination. CCIS, vol. 290, pp. 277-281. Springer-Verlag, Heidelberg.

O'Connor, R. V., \& Laporte, C. Y., 2012. Software project management in very small entities with ISO/IEC 29110 (pp. 330-341). Springer Berlin Heidelberg

O'Connor, R., \& Basri, S., 2012. The effect of team dynamics on software development process improvement. International Journal of Human Capital and Information Technology Professionals, 3(3), 13-26. 
O'Connor, R. V., \& Sanders, M. 2013. Lessons from a pilot implementation of ISO/IEC 29110 in a group of very small Irish companies. In Software Process Improvement and Capability Determination (pp. 243-246). Springer Berlin Heidelberg.

O'Connor, R. V., and Basri, S. 2014. Understanding the role of knowledge management in software development: a case study in very small companies, International Journal of Systems and Service-Oriented Engineering, Vol. 4, No. 1, pp. $39-52$.

O'Connor, R. V. and Laporte, C. Y., 2014. An Innovative Approach to the Development of an International Software Process Lifecycle Standard for Very Small Entities, International Journal of Information Technology and the Systems Approach, Vol. 7, No. 1, pp. 1-22.

Petkov, D., Edgar-Nevill, D., Madachy, R., \& O’Connor, R. 2008. Information systems, software engineering, and systems thinking: Challenges and opportunities. International Journal of Information Technologies and Systems Approach (IJITSA), 1(1), 62-78.

Ribaud, V., Saliou, P., O’Connor, R., Laporte, C.Y.: 2010. Software Engineering Support Activities for Very Small Entities. In: Riel, et al. (eds.) Systems, Software and Services Process Improvement. CCIS, vol. 99, pp. 165-176. Springer-Verlag, Heidelberg.

Statistics Canada. 2008. Available at: http://www.ic.gc.ca/sbstatistics 